\title{
The role of generalization in the acquisition of autoshaped keypecking in pigeons
}

\author{
RICHARD H. ETTINGER \\ Washington State University, Pullman, Washington 99164 \\ MICHAEL D. FINCH \\ Western Washington University, Bellingham, Washington 98225 \\ and \\ FRANCES K. McSWEENEY \\ Washington State University, Pullman, Washington 99164
}

\begin{abstract}
Two experiments investigated the role of generalization in the acquisition of autoshaped keypecking. In Experiment 1, 20 pigeons were exposed to an autoshaping procedure in the presence or absence of food magazine illumination. Pigeons did not peck a lighted response key when the food magazine was not illuminated, but they did reliably peck the key when the magazine was illuminated. In Experiment 2, 12 pigeons were exposed to an autoshaping procedure in the presence of two keylights. One keylight although dissimilar in hue to the magazine light, perfectly predicted reinforcement. A second keylight, similar in hue to the magazine light, never predicted reinforcement. Eleven of the 12 pigeons directed their initial keypeck toward the independent (generalized) keylight. Responding later shifted to the predictive light. These results suggest that generalization plays an important role in the acquisition of autoshaped keypecking.
\end{abstract}

Traditionally, the keypeck has been considered an operant behavior, shaped by its consequences. However, the autoshaping procedure has blurred the distinction between behaviors that are governed by operant conditioning and those governed by classical conditioning. Autoshaping procedures demonstrate that pigeons will peck a key as the result of response-independent pairings of a keylight stimulus with food (Brown \& Jenkins, 1968). The autoshaping procedure strongly resembles traditional classical conditioning procedures (Gamzu \& Williams, 1971). A keylight stimulus (CS) preceding the delivery of grain (UCS) comes to evoke pecking responses (CR) following several paired presentations.

Hearst and Jenkins (1974) proposed an explanation of the results of autoshaping procedures. They argued that the classical-operant distinction should be abandoned or drastically reworked. As an alternative, they suggested that animals direct their behavior toward the stimulus that best predicts the delivery of a reinforcer. Their theory is based on studies which show that many stimulus-directed responses as well as the results of the autoshaping experiments may be due to classical conditioning (Hearst \& Jenkins, 1974; Wasserman, 1973).

Requests for reprints should be sent to Richard H. Ettinger, Department of Psychology, Washington State University, Pullman, Washington 99164. Experiment 1 was conducted independently and concurrently with Davol, Steinhauer, and Lee (Experiment 2, 1977).
Steinhauer, Davol, and Lee (1976) proposed a second explanation of responding during autoshaping procedures. They suggested that the magazine light may acquire stimulus control over pecking at the food magazine. Pecks to the lighted food magazine are reinforced because the pigeon obtains food. Pecks to the unlighted food magazine are not reinforced because they do not obtain food. Pigeons may peck at the lighted key during autoshaping procedures as a result of generalization from the lighted food magazine.

The generalization theory predicts that the magazine light should be a significant feature in the acquisition of keypecking during autoshaping procedures. A study by Gilbert (1973) may support this claim. Gilbert reported that keypecking was less likely to occur when the keylight was unshielded. An unshielded keylight would allow light to diffuse into the food magazine when the magazine did not present grain. Therefore, pecking would not be differentially reinforced in the presence of light, and fewer keypecks might result from generalization. A study by Wasserman and McCracken (1974) provides mixed support for the theory. Their study found that the magazine light was important to the emergence of autoshaped keypecking: Keypecking was disrupted when the food magazine was illuminated at the same time as the response key was illuminated. However, Wasserman and McCracken concluded that generalization from the magazine light to the keylight was not responsible for the acquisition of autoshaped keypecking. Key- 
pecking occurred during a procedure that employed a red light and a white feeder. The authors concluded that generalization should not occur between red and white lights.

The present experiments test these theories of the acquisition of keypecking during autoshaping procedures. Experiment 1 examines the importance of generalization in the acquisition of keypecking. Experiment 2 pits a prediction of the sign-tracking theory of Hearst and Jenkins (1974) against a prediction of the generalization theory of Steinhauer et al. (1976).

\section{EXPERIMENT 1}

Experiment 1 examined the importance of generalization in the acquisition of autoshaped keypecking. Autoshaping was conducted with the magazine light on for one group of pigeons and with the light off for a second group. Autoshaping should not be observed in the nonilluminated condition if keypecking occurs as the result of generalized pecks from the lighted food magazine.

\section{Method}

The subjects were 20 naive White Carneaux pigeons maintained at $80 \%$ of their normal body weight. The subjects were randomly assigned to one of two groups and to one of three soundproof chambers equipped with Grason-Stadler pigeon stations, white noise, and a chamber light.

Magazine training. All of the subjects received $10 \mathrm{~min}$ of magazine training before the beginning of the experiment. Magazine training consisted of leaving the food magazine in the operating position until the subject approached and fed. Once the subject fed, the magazine was operated intermittently for the 4-sec durations, independent of the bird's behavior, for the duration of the 10-min period. Subjects in Group 1 received magazine training and autoshaping with the magazine illuminated with white light during its operation. Group 2, on the other hand, received magazine training and autoshaping with the magazine light off.

Experimental training. The experiment was conducted in two phases, using a procedure similar to that described by Brown and Jenkins (1968, Experiment 1). In Phase 1, autoshaping for Group 1 was conducted in two sessions, each consisting of 80 presentations of an 8-sec white keylight, followed immediately by a 4-sec illuminated food magazine operation. The food magazine was also illuminated with white light. The keylight was presented on a variable time (VT) 60 -sec schedule. A peck to the lighted key had no effect on keylight duration. During the intertrial interval, the keylight was off. A peck during the intertrial interval delayed the appearance of the next trial by an additional $60 \mathrm{sec}$. The chamber light was on throughout the experiment.

The subjects in Group 2 received two sessions following the same procedure as that used with Group 1, except that the food magazine was not illuminated during its operation. Phase 2 consisted of repeating the experiment with the procedures for Groups 1 and 2 reversed.

\section{Results and Discussion}

The mean for all subjects of the cumulative number of trials during which keypecking had occurred were plotted as a function of trial number for Phases 1 and 2. The data from Phase 1 (in Figure 1) show that food magazine illumination is a crucial feature of the autoshaping procedure, as demonstrated by Davol, Steinhauer, and Lee (1977, Experiment 2). None of the subjects in Group 2 (no-light condition) acquired the keypeck response indicative of autoshaping. On the other hand, 9 of the 10 subjects in Group 1 (light condition) acquired the keypeck response in a manner similar to that reported in other studies.

Figure 2 presents the mean for all subjects of the cumulative number of trials during which keypecking occurred, plotted as a function of trial number during Phase 2. The high average rate of responding emitted by Group 1 shows that keypecking was not disrupted

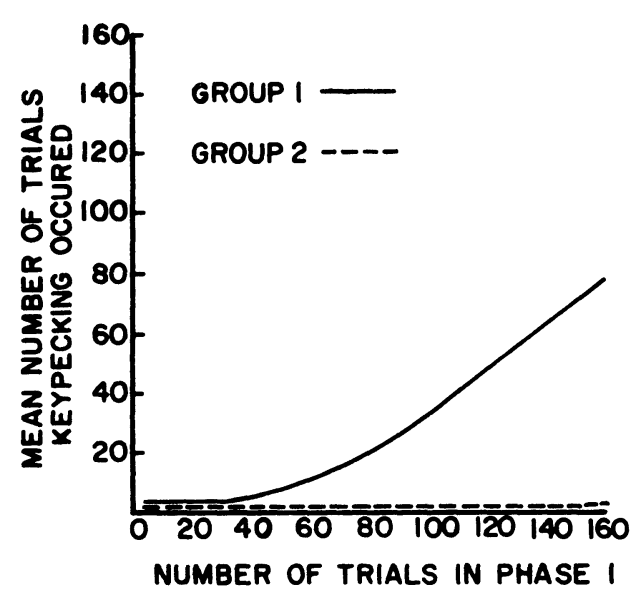

Figure 1. Mean for all subjects of the cumulative number of trials during which keypecking occurred as a function of trial number for Phase 1. Group 1 received illumination of the food magazine during its operation. The magazine was not illuminated for Group 2.

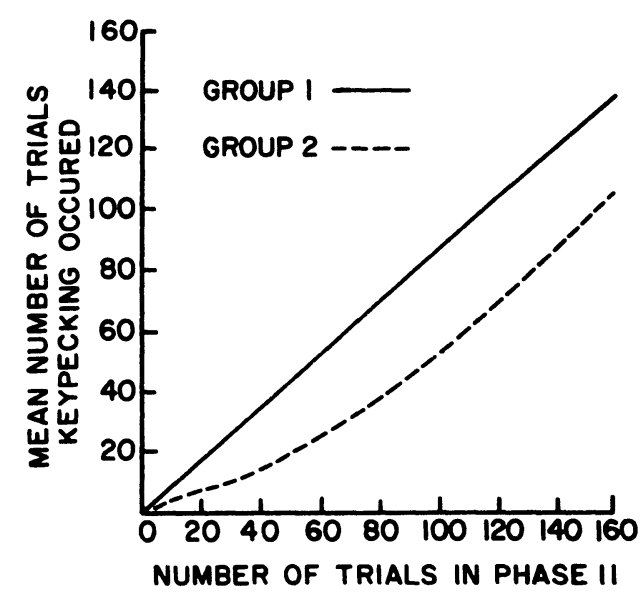

Figure 2. Mean for all subjects of the cumulative number of trials during which keypecking occurred as a function of trial number for Phase 2. The magazine was not illuminated during operation for Group 1, but was for Group 2. 
by the absence of illumination of the food magazine, once pecking had been established. The responding emitted by Group 2 indicated that a failure to peck the key in the absence of food magazine illumination did not prevent keypecking when the food magazine was illuminated later.

These results support a prediction of the generalization theory of autoshaping. The theory predicts that subjects should not peck the illuminated key when the food magazine is not illuminated. Keypecks should be most likely when the key and magazine are illuminated similarly, because generalization between the two should be greatest under these conditions.

However, these results do not necessarily refute the sign-tracking, or classical conditioning, theories of autoshaped responding. These theories might predict the present results under two sets of circumstances. First, they might argue that the magazine light, not the grain, was the UCS in autoshaping procedures. If this were true, turning off the magazine light would remove the UCS. The subjects in Group 2 would not emit the conditioned keypeck because they never experienced CS-UCS pairings. However, a study by Jenkins and Moore (1973) suggests that food, not the light, is the UCS in autoshaping procedures. This study showed that autoshaped responses resembled eating when the UCS was access to a lighted food magazine but resembled drinking when the UCS was access to a lighted water dipper. It might be argued that the CR should be the same in both cases if the UCS was the same, that is, the light, rather than the food or water. However, a more conclusive study should be conducted. It would present an empty but illuminated food magazine following the keylight in an autoshaping procedure. The subjects should peck the key if the magazine light is the UCS in a classical conditioning explanation of autoshaping: They would have received CS-UCS pairings. The magazine light could not be the UCS if naive subjects did not peck the key under these circumstances.

Second, the theories might argue that the CS-UCS relationship was disrupted by the removal of the magazine light for Group 2. The relationship would be completely disrupted if the subjects did not eat from the unlighted magazine. It would be partially disrupted if the subjects did not eat as much from the unlighted as from the lighted magazine. Observation of the subjects in Group 2 showed that they did orient toward the keylight and consistently fed from the dark food magazine following keylight termination. However, it is possible that Group 2 ate less food from the unlighted magazine than Group 1 ate from the lighted magazine. The subjects in Group 2 should not condition as well as those in Group 1 if the UCS was poorer for Group 2. A study should be conducted that measures the amounts eaten from lighted and unlighted food magazines.

\section{EXPERIMENT 2}

Experiment 2 tested the predictions of the generalization and sign-tracking theories of the acquisition of autoshaped responding in a more conclusive way. It employed two keylights: One, although dissimilar in hue to the magazine light, perfectly predicted food presentations. A second keylight, similar in hue to the magazine light, never predicted food presentations. If sign-tracking accounts for the acquisition of keypecking during autoshaping procedures, the first keypeck should be directed toward the predictive keylight. If generalization accounts for the acquisition of keypecking in autoshaping, keypecks should be directed toward the keylight similar in hue to the food magazine.

Several studies have demonstrated that, given an alternative, pigeons direct their initial keypeck toward a stimulus of similar hue to the magazine light (Davol et al., 1977; Fisher \& Catania, 1977; Sperling, Perkins, \& Duncan, 1977). However, in the studies by Davol et al. (1977) and by Fisher and Catania (1977), the light that was similar in hue to the magazine light also predicted the reinforcer. Therefore, these studies do not conclusively show that generalization from the magazine to the keylight produced keypecking. The results reported by Sperling et al. (1977, Experiment 4) were more conclusive. They demonstrated that initial keypecks are directed toward a stimulus of the same hue as the magazine light even when the stimulus did not immediately precede the presentation of the food magazine. The stimulus, presented for a variable period of time averaging $30 \mathrm{sec}$, was never followed by food. But it was followed by a 6-sec stimulus that did predict food. Therefore, the stimulus the subjects pecked may have weakly predicted food. The present experiment is similar to the Sperling et al. study except that it more conclusively prevented the stimulus that was similar in hue to the magazine light from predicting the presentation of food.

\footnotetext{
Method

The subjects were 12 naive homing pigeons maintained at $80 \%$ of their normal body weight. The subjects were randomly assigned to one of four groups and to one of two soundproof chambers equipped with Grason-Stadler two-key pigeon stations, white noise, and a chamber light.

Magazine training. Magazine training was conducted in a manner similar to that described in Experiment 1, with the exception that pigeons in Groups 1 and 2 were magazine trained and autoshaped with a green magazine light. Pigeons in Groups 3 and 4 were magazine trained and autoshaped with a red magazine light.

Experimental training. The pigeons in Experiment 2 were exposed to one of four autoshaping conditions. Groups 1 and 2 received two sessions each, consisting of 80 pairings of an 8-sec red keylight, followed immediately at the offset of the keylight by a 4-sec food magazine operation. The food magazine, for Groups 1 and 2, was illuminated with a green light during its operation. The red keylight was presented on a VT $60-\mathrm{sec}$ schedule. An 8-sec green keylight, also presented on a VT 60 -sec schedule, was operated independently of food presentations. To
} 
prevent the simultaneous occurrence of both keylights and the possibility of food presentation following the independent keylight, the occurrence of either delayed the presentation of the alternate keylight for $8 \mathrm{sec}$. A peck to either keylight had no effect on keylight duration. A peck during either intertrial interval delayed the occurrence of both keylights by an additional $60 \mathrm{sec}$. To control for position preferences, the positions of the predictive and independent keylights were reversed for Groups 1 and 2.

As a control for color preferences, Groups 3 and 4 received two similar sessions. However, the food magazine was illuminated with a red light during its operation, the independent keylight was red, and the predictive keylight was green. Keylight position preference was again controlled for by position reversal between the groups.

\section{Results and Discussion}

Since Experiment 2 was concerned with the acquisition of keypecking in autoshaping, initial keypecks were recorded. The condition and trial number of first keypecks are presented in Table 1. As shown in Table 1, 11 of the 12 pigeons directed their initial keypecks toward the independent (generalized) keylight. That is, generalization appears to have a more significant role in directing the first keypeck during autoshaping procedures than does "sign-tracking." These results, along with the results of Experiment 1, suggest that generalization is a critical feature in the acquisition of keypecking in the autoshaping paradigm.

Although initial responding was directed toward the independent (generalized) keylight, the responses rapidly disappeared and keypecking shifted to the predictive light. The shift of responding to the stimulus that preceded food may have occurred either because the stimulus was predictive of food or because of superstitious conditioning. Responses directed toward the predictive stimulus may have been reinforced because they were followed by food presentation. Responses toward the independent keylight were not followed by food.

The stimulus-reinforcer and response-reinforcer explanations of the maintenance of responding during autoshaping procedures can be tested by conducting an experiment employing an omission procedure (Deich \& Wasserman, 1977). If the subjects pecked the predictive key because of superstitious conditioning, they should stop pecking this key if the pecks cancelled the following food presentations. If the subjects pecked the predictive key because it predicted food, they should peck the key even when pecks cancel food, if the stimulus is still occasionally followed by food.

\section{GENERAL DISCUSSION}

The results of Experiments 1 and 2 clearly suggest that generalization is important to the acquisition of keypecking in the autoshaping paradigm. The maintenance of keypecking, however, appears to be dependent upon stimulus-reinforcer and/or response-reinforcer relationships. This conceptualization of the acquisition of keypecking in autoshaping is not consistent with the view that autoshaped keypecks are elicited by stimulus-
Table 1

Condition and Trial of First Keypeck

\begin{tabular}{cccc} 
Pigeon & $\begin{array}{c}\text { Independent } \\
\text { Nonpredictive } \\
\text { Key }\end{array}$ & Pigeon & $\begin{array}{c}\text { Independent } \\
\text { Nonpredictive } \\
\text { Key }\end{array}$ \\
\hline 1 & 20 & 7 & 11 \\
2 & 13 & 8 & 47 \\
3 & 74 & $9 *$ & \\
4 & 7 & 10 & 16 \\
5 & 9 & 11 & 10 \\
6 & 33 & 12 & 63 \\
\hline
\end{tabular}

*Pigeon 9 directed initial keypecks to the predictive keylight (Trial 16).

reinforcer pairings. It is consistent, however, with a more recent interpretation that the acquisition of autoshaped keypecks is a result of generalization of pecking at the lighted food magazine to pecking at the lighted key (Davol et al., 1977; Fisher \& Catania, 1977; Sperling et al., 1977).

\section{REFERENCES}

Brown, P. L., \& Jenkins, H. M. Autoshaping of the pigeon's keypeck. Journal of the Experimental Analysis of Behavior, 1968, 11, 1-8.

Davol, G. J., Steinhauer, G. D., \& Lee, A. The role of preliminary magazine training in the acquisition of the autoshaped key peck. Journal of the Experimental Analysis of Behavior, 1977, 28, 99-106.

Deich, J. D., \& Wasserman, E. A. Rate and temporal pattern of key-pecking under autoshaping and omission schedules of reinforcement. Journal of the Experimental Analysis of Behavior, 1977, 27, 399-405.

Fisher, M. A., \& Catania, A. C. Autoshaping: Relation of feeder color to choice of key color. Bulletin of the Psychonomic Society, 1977, 9, 439-442.

Gamzu, E., \& Williams, D. R. Classical conditioning of a complex skeletal response. Science, 1971, 171, 923-925.

GILBERT, R. M. Keypecking by pigeons in an imperfect environment for autoshaping. Bulletin of the Psychonomic Society, 1973, 2, 10-12.

Hearst, E., \& Jenkins, H. M. Sign-tracking: The stimulusreinforcer relation and directed action. Austin, Tex: The Psychonomic Society, 1974.

Jenkins, H. M., \& Moore, B. R. The form of the autoshaped response with food and water reinforcers. Journal of the Experimental Analysis of Behavior, 1973, 20, 163-181.

Sperling, S. E., Perkins, M. E., \& Duncan, H. J. Stimulus generalization from feeder to response key in the acquisition of autoshaped pecking. Journal of the Experimental Analysis of Behavior, 1977, 27, 469-474.

Steinhauer, G. D., Davol, G. H., \& Lee, A. Acquisition of the autoshaped key peck as a function of amount of preliminary magazine training. Journal of the Experimental Analysis of Behavior, 1976, 25, 355-359.

Wasserman, E. A. Pavlovian conditioning with heat reinforcement produces stimulus-directed pecking in chicks. Science, 1973, 181, 875-877.

Wasserman, E. A., \& McCracken, S. B. The disruption of autoshaped key-pecking in the pigeon by food tray illumination. Journal of the Experimental Analysis of Behavior, 1974, 22, 39-45.

(Received for publication June 22, 1978.) 